\title{
The problem of Lyme borreliosis infections in urban and rural residents in Poland, based on National Health Fund data
}

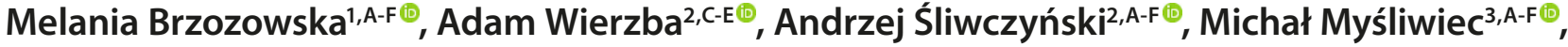 \\ Krzysztof Kozłowski ${ }^{4, D-F} \oplus$, Waldemar Wierzba ${ }^{2, A-F} \oplus$ \\ ${ }^{1}$ Department of Drug Management, National Health Fund, Poland \\ ${ }^{2}$ University of Humanities and Economics, Łódź, Poland \\ ${ }^{3}$ State University of Applied Sciences, Łomza, Poland \\ ${ }^{4}$ Department of Constitutional Law, Jagiellonian University, Kraków, Poland \\ A - Research concept and design, B - Collection and/or assembly of data, C - Data analysis and interpretation, \\ $D$ - Writing the article, $E$ - Critical revision of the article, $F$ - Final approval of article
}

Brzozowska M, Wierzba A, Śliwczyński A, Myśliwiec M, Kozłowski K, Wierzba W. The problem of Lyme borreliosis infections in urban and rural residents in Poland, based on the National Health Fund data. Ann Agric Environ Med. 2021; 28(2): 277-282. doi: $10.26444 / a a e m / 121056$

\begin{abstract}
Introduction and objective. Some fragmentary studies show that the incidence of Lyme borreliosis in Poland is increasing. It has been generally accepted that the most affected are forestry workers and farmers. The aim of the study is to compare the incidence of borreliosis in urban and rural residents in 2008-2016.

Materials and method. Databases on Lyme borreliosis from the National Health Fund and Central Statistical Office in Poland were analyzed. For each patient, ambulatory or discharged from every hospital, the diagnosis was compulsorily reported as encoded following the International Classification of Diseases.

Results. A steadily increasing number of patients with borreliosis in Poland was found, which doubled in 2008 - 2016. The incidence was similar in urban and rural residents. In all the provinces in Poland, an increase in incidence of borreliosis was observed, although there were big differences between them. The highest frequency of borreliosis was in Podlasie and Warmia-Masuria provinces. The lowest incidence of borreliosis was noticed in Wielkopolska province. In the most of provinces the increase in the incidence of borreliosis was steady, except Warmia-Masuria, where it was very low in 2008, and soaring since 2011. The number of cases per year between 2008 - 2016 increased in both in males and females.

Conclusions. The results suggest the need for higher awareness of the risk of Lyme borreliosis in urban residents, because the incidence of Lyme borreliosis is growing independently of the place of residence. Prompt measures to prevent tick bites and appropriate education are urgently needed.
\end{abstract}

\section{Key words}

Poland, epidemiology, Lyme borreliosis

\section{INTRODUCTION}

Lyme borreliosis (LB) is the most common tick-borne disease caused by a group of bacteria called Borrelia burgdorferi sensu lato. The disease is transmitted mainly by Ixodes ricinus tick nymphs and females inhabiting meadows and forests, but also in urban parks and roadsides. Ticks feed on many species of animals, both wild and domestic. A risk of tick exposure is due to occupational and recreational activities in contact with nature.

Clinically, borreliosis can be divided into three stages: early, early disseminated and late disseminated [1]. The typical feature of early Lyme borreliosis (LB) is erythema migrans, a slowly expanding red or bluish-red skin lesion near the bite site, which appears in $60 \%-80 \%$ of people after 2-30 days [2]. It is diagnosed and treated with antibiotics, without any laboratory tests. A rare form of early borreliosis is localized skin lymphoma.

In some patients, the bacteria can disseminate and cause early disseminated Lyme borreliosis, manifesting mainly as

Address for correspondence: Waldemar Wierzba, University of Humanities and Economics, Łódź, Poland

E-mail: wwierzba@post.pl

Received: 06.01.2020; accepted: 21.04.2020; first published: 06.05.2020 arthritis, myocarditis or neuroborreliosis. Late borreliosis may manifest as acrodermatitis chronica atrophicans, arthritis or neuroborreliosis [2, 3]. Diagnosis of late LB rests on careful clinical evaluation and serologic testing, after exclusion of other diagnoses. Serological testing for the presence of antibodies against Borrelia burgdorferi is also recommended in cases of the atypical or disseminated disease. It has generally been accepted that the most affected are farmers and forestry workers [2]. The aim of the present work was to compare the incidence of LB in Poland in 20082016, with particular attention to the incidence of the disease in urban and rural inhabitants.

\section{MATERIALS AND METHOD}

The analysis was based on data from the National Health Fund (the only public payer in Poland), which collects online electronic reports of all cases of borreliosis in Poland, including erythema migrans, both from out-patient clinics and hospitals. The diagnosis was reported encoded following the International Classification of Diseases (ICD10). In the ICD-10 classification, early disseminated and late manifestation of LB are grouped under the same code 
(A69.2). The use of the unique national ID number (PESEL) excluded the possibility of counting the same patient more than once. The exact number of patients diagnosed with borreliosis each year was analysed by means of Excel and Statistica 10. Demographic data were obtained from the Polish Central Statistical Office. Geographical distribution, based on patients' addresses, was assessed in relation to the population of the province.

The study was limited by the lack of differentiation between the forms of the disease which resulted from imperfections in the ICD-10 classification. Another limitation was the hyper-recognition of articular forms resulting from a large commercial market offering research, and excessive reporting to the State Sanitary Inspection and the National Health Fund.

\section{RESULTS}

In Poland between 2008 - 2016, a steadily increasing number of patients with diagnosed borreliosis has been observed. The incidence of the disease was higher in women than in men during 2008 - 2012 followed, by a higher increase in men since 2013, although the pattern of increased incidence was similar between genders (Tab. 1).

In general in Poland, about $96 \%$ of cases in which LB was diagnosed (principal or secondary), borreliosis was the principal diagnosis and remained quite stable during 2008 -2012, but since then has decreased to below 70\% (Tab. 2, Fig. 1).

In all the provinces in Poland an increase in the incidence of diagnosed borreliosis was observed in urban inhabitants, although there were big differences between provinces. The highest incidence of borreliosis was in the Podlasie and Warmia-Masuria provinces (in 2016, 43.17 and 45.48/100,000, respectively). The lowest incidence of borreliosis was noted in Wielkopolska, Kujawy-Pomerania, Opole, Lubuskie, and Łódź. In the majority of provinces, the increase in the incidence of borreliosis was steady, with the exception of Warmia-Masuria, where it was very low in 2008 and very high since 2011 (Tab. 3, Fig. 1).

In all the provinces, an increase in the incidence of diagnosed borreliosis in rural inhabitants was observed, although there were significant differences between them.

Table 1. Number of patients with Lyme borreliosis in Poland in years 2008-2016 (divided into sex)

\begin{tabular}{|c|c|c|c|c|c|c|c|c|c|}
\hline Sex & 2008 & 2009 & 2010 & 2011 & 2012 & 2013 & 2014 & 2015 & 2016 \\
\hline Female & 13,321 & 18,687 & 19,144 & 25,268 & 28,307 & 20,732 & 23,184 & 23,209 & 30,344 \\
\hline Male & 9,004 & 12,511 & 12,126 & 16,037 & 18,240 & 31,419 & 34,095 & 34,212 & 44,269 \\
\hline Total & 22,325 & 31,198 & 31,270 & 41,305 & 46,547 & 52,151 & 57,279 & 57,421 & 74,613 \\
\hline Female to Male ratio & 1.48 & 1.49 & 1.58 & 1.58 & 1.55 & 1.51 & 1.47 & 1.47 & 1.45 \\
\hline
\end{tabular}

Table 2. Number of patients with borreliosis as main diagnosis or comorbidity in Poland in 2008-2016

\begin{tabular}{lccccccccc}
\hline Diagnosis & 2008 & 2009 & 2010 & 2011 & 2012 & 2013 & 2014 & 2015 & 2016 \\
\hline Principal and secondary diagnosis & 22,325 & 31,198 & 31,270 & 41,305 & 46,547 & 52,151 & 57,279 & 57,421 & 74,613 \\
\hline Primary diagnosis & 21,356 & 29,872 & 30,063 & 39,939 & 44,998 & 36,023 & 37,622 & 35,493 & 50,916 \\
\hline$\%$ of primary diagnosis & 95.5 & 95.6 & 96.0 & 96.5 & 96.5 & 69.0 & 65.7 & 61.8 & 68.2 \\
\hline
\end{tabular}

Table 3. Morbidity rate (cases per 10,000 population) in urban inhabitants in the provinces of Poland in the years $2008-2016$

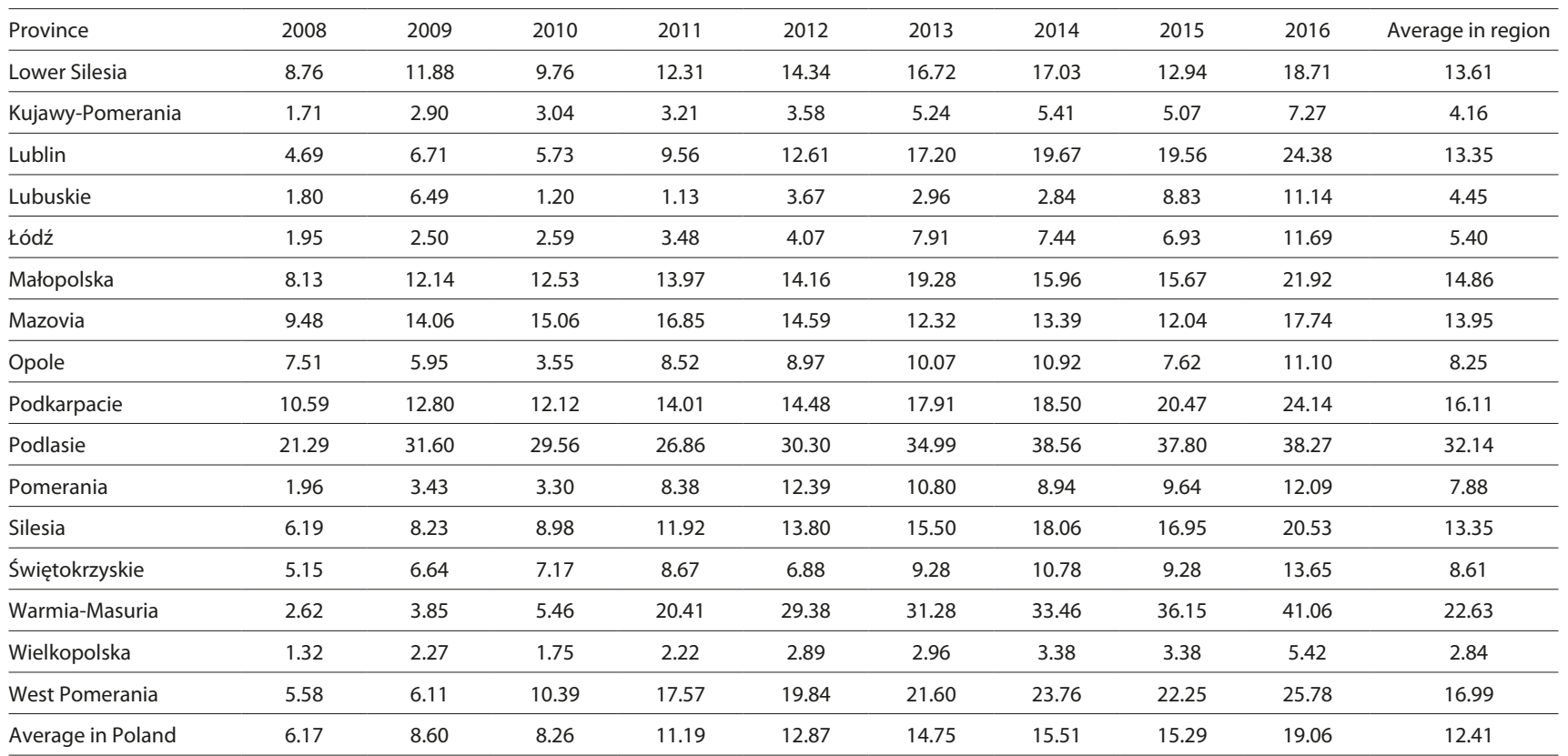




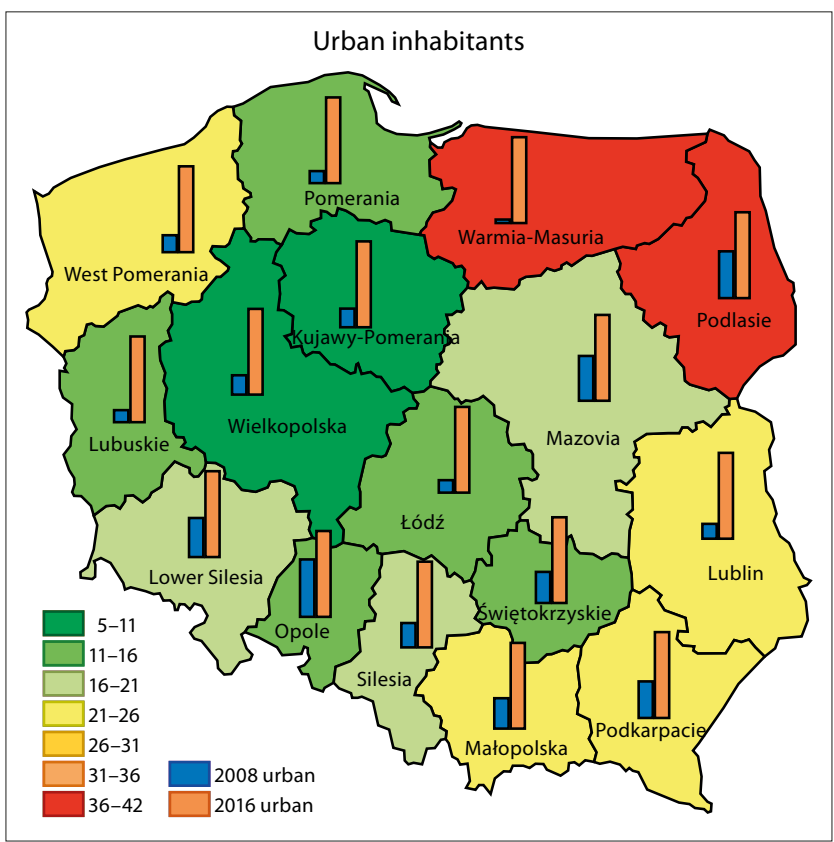

Figure 1. The mean values within the years 2008-2016 in particular provinces are showed in different colours in the map. Blue and orange bars show changes in morbidity index of borreliosis in 2016 as compared to 2008 in urban inhabitants in particular regions (cases per 10,000 of population

The highest incidence of borreliosis in rural inhabitants was in Podlasi, and since 2011, in Warmia-Masuria provinces (3.48 - 49.89/100,000 in 2016). The total incidence of borreliosis in 2016 in Podlasie and Warmia-Masuria was 43.17 and 45.48/100,000, respectively. The lowest incidence of borreliosis was noted in Wielkopolska, Kujawy-Pomerania, Lubuskie, and Łódź. In the largest number of provinces, the increase in the incidence of borreliosis was steady, except for Warmia-Masuria, where it was very low in 2008, and very high since 2011. The pattern of increasing incidence of borreliosis was similar in all provinces for the urban and rural inhabitants (Tab. 4, Fig. 2).

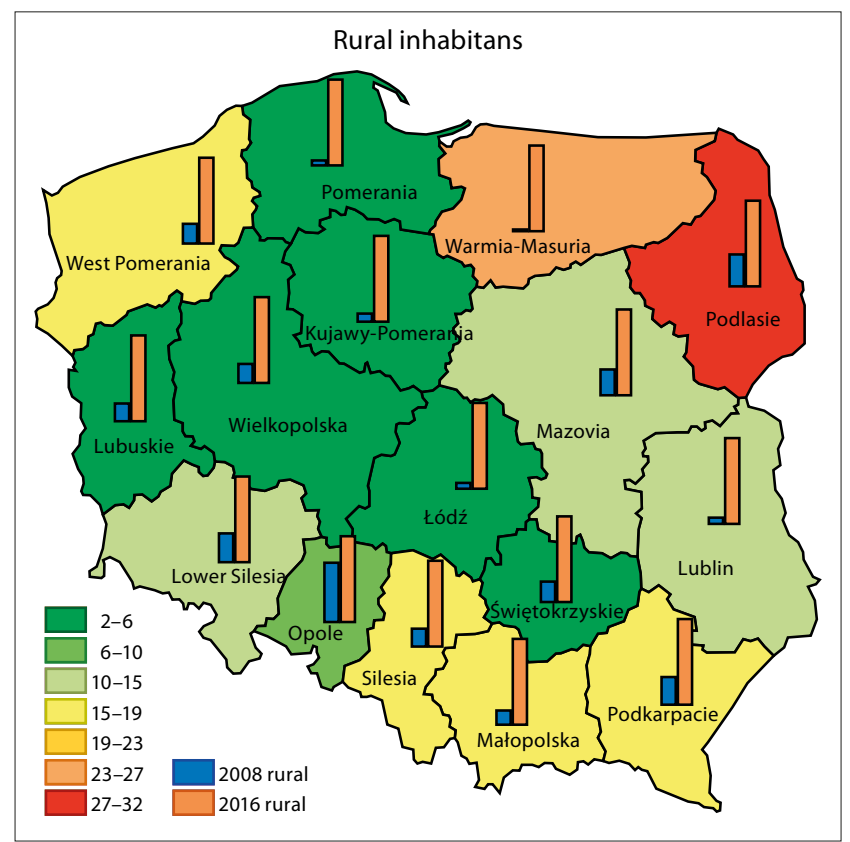

Figure 2. The mean values within the years $2008-2016$ in particular provinces are showed in different colours in the map. Blue and orange bars show changes in morbidity index of borreliosis in 2016 as compared to 2008 in rural inhabitants in particular regions (cases per 10,000 of population)

Figures 1-2 show a similar increase in diagnosed borreliosis in urban and rural inhabitants between 2008 - 2016. The highest morbidity index was observed in Warmia-Masuria and Podlasie provinces, both in urban and rural inhabitants. The lowest morbidity was observed in Wielkopolska and Kujawy-Pomerania. The highest rise in morbidity took place in Warmia-Masuria, Lublin, Pomerania, and Łódź provinces.

Table 4. Morbidity rate (cases per 10,000 population) in rural inhabitants of the provinces of Poland in the years $2008-2012$

\begin{tabular}{|c|c|c|c|c|c|c|c|c|c|c|}
\hline Voivodeship & 2008 & 2009 & 2010 & 2011 & 2012 & 2013 & 2014 & 2015 & 2016 & Average in region \\
\hline Lower Silesia & 7.61 & 7.52 & 7.94 & 9.55 & 12.79 & 13.29 & 14.58 & 13.48 & 20.66 & 11.94 \\
\hline Kujawy-Pomerania & 1.21 & 2.47 & 2.54 & 2.60 & 3.43 & 4.12 & 4.52 & 5.43 & 7.33 & 3.74 \\
\hline Lublin & 3.07 & 11.26 & 5.66 & 8.78 & 11.07 & 15.52 & 18.45 & 20.17 & 27.48 & 13.50 \\
\hline Lubuskie & 2.49 & 7.76 & 1.38 & 1.09 & 2.99 & 3.67 & 3.56 & 9.53 & 11.55 & 4.89 \\
\hline Łódź & 1.34 & 1.87 & 2.18 & 3.02 & 3.51 & 4.93 & 5.57 & 5.56 & 11.63 & 4.40 \\
\hline Mazovia & 6.95 & 9.92 & 9.33 & 10.39 & 9.60 & 8.56 & 11.60 & 12.86 & 18.32 & 10.84 \\
\hline Opole & 7.00 & 10.51 & 3.26 & 7.40 & 7.71 & 8.98 & 9.40 & 7.06 & 9.98 & 7.92 \\
\hline Podkarpacie & 9.60 & 34.66 & 12.25 & 13.03 & 13.96 & 16.60 & 20.37 & 22.28 & 26.21 & 18.77 \\
\hline Podlasie & 22.64 & 41.45 & 30.63 & 29.86 & 31.66 & 31.41 & 40.71 & 43.14 & 48.07 & 35.51 \\
\hline Pomerania & 1.29 & 2.16 & 2.11 & 5.07 & 7.44 & 6.64 & 5.93 & 6.97 & 11.35 & 5.44 \\
\hline Świętokrzyskie & 3.17 & 9.06 & 4.22 & 5.25 & 4.36 & 5.56 & 7.56 & 6.87 & 11.11 & 6.35 \\
\hline Warmia-Masuria & 3.48 & 5.60 & 5.66 & 24.30 & 34.73 & 35.45 & 39.34 & 43.46 & 49.89 & 26.88 \\
\hline Wielkopolska & 1.28 & 2.76 & 1.82 & 1.78 & 2.34 & 2.24 & 2.46 & 2.74 & 4.44 & 2.43 \\
\hline West Pomerania & 7.07 & 6.26 & 11.49 & 15.43 & 17.51 & 17.96 & 21.57 & 21.44 & 24.94 & 15.96 \\
\hline Average in Poland & 5.75 & 11.14 & 7.58 & 10.34 & 12.19 & 13.39 & 15.72 & 16.72 & 21.41 & 12.69 \\
\hline
\end{tabular}




\section{DISCUSSION}

This study shows for the first time that LB incidence in Poland has been steadily increasing and has doubled between 2008 - 2016 both in urban and rural inhabitants.

In all the provinces, an increase in the incidence of borreliosis was observed, although there were big differences among them. The predominance of LB in females in Poland may be explained by the overall predominance of women, and higher prevalence of females visiting parks with their children. Recent data from the United States has shown a slight predominance of LB among males in the States with the highest incidence of LB [4].

In Poland, the highest rate of borreliosis was in Podlasie and Warmia-Masuria provinces (over 40 cases per 100,000 population). The lowest incidence of borreliosis was noted in Wielkopolska, Kujawy-Pomerania, Lubuskie and Łódź $(<5 / 100,000)$. It is of interest that Lubuskie, with one of the lowest rate of borreliosis, is particularly abundant in forests (almost 50\% of the area), whereas Podlasie and WarmiaMasuria provinces, with the highest rate of Lyme borreliosis, have only about $30 \%$ of forests. In the majority of provinces, the increase in the incidence of borreliosis was steady, except for Warmia-Masuria where it was very low in 2008, and very high since 2011. It is of interest that in Poland there were warm winters in 2006-2007 and 2007-2008, which might have influenced the rise in cases of borreliosis two years later - in 2009. Accurate data on forest cover (percentage of forest area in a given province to the total area) is given in the Statistical Yearbooks for Forestry in the Central Statistical Office. For example, the forest cover in the Warmian-Masurian Province is $31 \%$, Podlasie $-30.7 \%$, Wielkopolskie $-25.7 \%$, KujawskoPomorskie - 23.4\%, Opolskie -26.6\%, Lubuskie - 49.2\%, and Łódzkie - 21.3\% [5].

The increased incidence of urban LB is difficult to explain, although increased awareness and climate warming favouring the growth of vegetation and spreading of medium- and large-sized animals in urban surroundings, may additionally be explained by possible sexual transmission [6]. It is difficult to explain the sudden rise of LB cases in urban and rural inhabitants of Warmia-Masuria between 2008 - 2016, but there is a possibility that the awareness of LB increased within that time, partly due to the growing interest of various public media in Poland.

The strength of the current study is the completeness of the data, with only $0.16 \%$ of lacking or erroneous data. A weakness of the paper, however, is the mixing of early and late manifestations of LB, grouped under the same code (A69.2) in the ICD-10 classification, which was the basis of the study. It was also not able to discern between incidence and prevalence of borreliosis, as both were reported in common. Notwithstanding this, the prevalence of new cases is obvious, as early borreliosis is cured in most cases, and late borreliosis consists of not more than $10 \%$ of the total figure.

Worldwide, there is the problem of the great variability in reporting and vigilance of borreliosis [7]. The national statistics on the epidemiology of borreliosis in Poland are based on individual notifications of suspected Lyme disease, submitted to the National Institute of Public Health-National Institute of Hygiene (NIZP-PZH) by the Provincial SanitaryEpidemiological Stations. Paradowska-Stankiewicz et al. reported that in 2012 there were 8,782 registered cases of Lyme disease, which was $4.3 \%$ higher than in the previous year. The overall incidence in Poland amounted to 23.8 per 100,000 population. The highest incidence rate was recorded in Podlaskie province - 75.5 per 100,000 population. In 2012 in Poland, 2,063 people were hospitalized due to Lyme disease [8]. The data from NIZP-PZH show about 8 times fewer cases than in the current analysis, despite including not only confirmed cases but also suspected cases. Such a big difference may be caused by under-reporting by physicians and laboratory technicians because such reporting can it takes some minutes, resulting in a low willingness to fill in an additional questionnaire. On the other hand, the presented data might exaggerate the numbers, as they contain all patients visiting doctors in Poland, with suspected or confirmed borreliosis. The possibility of over-diagnosis might also be influential, but applied mainly to a minority of patients with late borreliosis [9]. Although they may include unconfirmed cases, not all patients diagnosed with LB visit doctors. A drawback of the presented data is a lack of knowing how many reported cases were confirmed by laboratory tests; therefore it should be considered that some cases were over-diagnosed.

The diagnosis of LB in Poland is based on the 2015recommendations of the Polish Society of Epidemiology and Infectious Diseases [2], which do not differ from the European recommendations presented by Stanek et al. $[3$, based primarily on clinical presentation (particularly erythema migrans) and on the history of a tick bite with a supplementary role of the serological tests (ELISA, Western blot). The antibodies may not be present in the early stages and misleading in endemic areas, and are therefore not advised in the diagnosis of erythema migrans [10]. Obtaining bacterial cultures from clinical samples or the detection of bacterial DNA using the PCR methods are rarely performed, although strongly advised when there are difficulties in diagnosing a tick-borne disease when only non-specific symptoms are present. On the other hand, not all cases of tick bites are noticed because the tick saliva contains an anaesthetic. Hofhuis et al. found that in the general population of The Netherlands in 2007, for every 60 tick bites only one case was consulted by a general practitioner for erythema migrans [11]. Additionally, at least $20 \%$ of acute LB cases show no sign of erythema migrans, which is a typical feature of the disease and enables to make the right diagnosis. Misdiagnosis of late borreliosis is even higher, despite recommendations of the Polish Society of Epidemiology and Infectious Diseases [2].

Comparison of LB incidence rates is still very difficult in the absence of the standardized reporting procedures [7].

In our study, the geographical distribution of borreliosis, based on the addresses of the patients, was assessed in relation to the population of the voivodship. Although north-east part of Poland, in which the incidence of LB was the highest, is abundant in forests, the south-west regions with the lowest incidence of borreliosis also have the large forest areas. Climate changes creating more favourable conditions for ticks and their wildlife hosts are probable explanations for the increase of incidence of LB in Poland. Zeman and Benes observed the rise of LB cases in 1997-2010 in the Czech Republic which was solely due to infections acquired at or near patients' homes $(<5 \mathrm{~km})$, while the number of cases acquired further away was decreasing [12].

Unfortunately, we do not have data on the type of areas where tick bites took place. We are also unable to assess the nature of causes leading to the hospitalization of the 
patients. In addition, we do not have data to estimate the proportion of positive laboratory test results. Knowing unique identification numbers (PESEL) of the patients, we were able to establish their place of residence and gender and also to avoid a risk of counting the same patient more than once.

Poland has been an endemic area for LB. It has been known that the risk of borreliosis is greater among people either resting or working in the forest or meadow surroundings (i.e., foresters, farmers, hunters) [13]. Our data suggest that it has changed, with the steadily increasing risk of LB among city inhabitants.

There are various reasons for the increase in the incidence of LB in the cities in Poland, from an increased awareness and increased testing to climate changes which cause spreading of ticks to cities. As LB is a tick born infection, the increase in the number and in activity of ticks and the growing number of infected ticks may be at play. The growing population of vectors and the number of their reservoirs may also be related to climatic conditions, like temperature, humidity. Mild winters and pollution, as well as vegetation and topography of the terrain, should also be taken into account. Tick distribution and activity are also influenced by the presence of hosts of the various tick developmental stages which participate in the spread of Borrelia burgdorferi. Various animals, mostly small rodents, and passerine birds are competent reservoirs of the bacteria, as active bacteremia develops in their organisms, enabling ticks to spread out.

Kiewra et al. studied the prevalence of Borrelia burgdorferi sensu lato in Ixodes ricinus and analysed the temporal abundance of ticks in relation to epidemiological data on LB incidence in Lower Silesia region. Their results point to a correlation between tick temporal abundance in southwestern Poland and the high incidence of LB in humans [14]. Strzelczyk et al. found that $15 \%$ of ticks were infected by B. burgdorferi sensu lato, which increases the risk of human infections in the recreational areas of southern Poland [15]. Buczek et al. found that a threat of an attack of infected Ixodes ricinus is higher in the urban localities than in the suburban sites in Silesia region in Poland [16]. The highest percentage of Ixodes ricinus females infected with these bacteria was found in the city park in Chorzow (9.4\%), and in a site at the city borders $(5.9 \%)$, whereas the lowest percentage was noted in the forest site (3.12\%). The highest occurrence of spirochetes in Ixodes ricinus females collected in the urban park may be related not only to the presence of competent reservoirs of these pathogens but also to the possibility of their rapid spread by domestic animals. Wojcik-Fatla et al. found an increasing number of ticks infected with Borrelia burgdorferi sensu lato in the years 2008-2009 and 2013-2014 in Lublin province (eastern Poland) - from 6.0 to $15.3 \%$ [17].

The overall mean occurrence of Borrelia burgdorferi sensu lato in ticks in Europe is 13.7-18.6\% for adult forms and 10.1\% for nymphs. In Central Europe (Austria, Czech Republic, Germany, Switzerland, Slovenia and Slovakia) $22.3 \%$ of adult forms of Ixodes ricinus ticks removed from human bodies were found to carry spirochetes in 2012 (for nymphs the occurrence of Borrelia spirochetes was $11 \%$ and for adult forms $>20 \%$ ) [18].

Ixodes ricinus may be infected not only with Borrelia spirochetes but also Babesia microti (up to $32,3 \%$ of the nymphs from Slowinski National Park in Poland) and, less frequently, with Anaplasma phagocytophilum and
Toxoplasma gondii [19]. Coinfections of Borrelia mostly with Anaplasma were observed in 5,1\% of patients hospitalized in Bialystok [20].

There are 65 endemic or potentially endemic countries for LB all over the world [14]. The statistics show high variability in LB prevalence rates within the European countries. The highest incidence of LB was reported in southern Sweden $(69 / 100,000)[21]$ while the lowest - in Italy $(0.01 / 100,000)$ [15]. In countries neighbouring Poland, the incidence of borreliosis varied from $11.3 / 100,000$ in 1999 to $19.2 / 100,000$ in 2008 in Slovakia and from $17.8 / 100,000$ in 2000 to $37.3 / 100,000$ in 2006 in Germany. In 2013 in Belarus, about 11 cases per 100,000 population were reported [18]. The number of LB cases is also increasing annually in the Netherlands, the Czech Republic and Hungary. Similar trends towards an increased borreliosis incidence are observed in other European countries. On the other hand, a decrease in the number of cases is observed in France and Switzerland. In Belgium, the incidence of the disease was quite stable in the decade until 2012 [22].

\section{CONCLUSIONS}

1. The highest incidence of Lyme disease was recorded in Podlasie and Warmian-Masurian voivodships (43.17 and $45.48 / 100,000$ respectively in 2016), this phenomenon may correlate with the largest percentage of forests in these voivodships.

2. The lowest incidence of Lyme disease was recorded in Wielkopolska, Kujawsko-Pomorskie, Opole and Łódź. These voivodships have the smallest percentage of forest area in relation to the entire voivodship. An interesting exception is the Lubuskie Province, which, with high forest cover, has a low incidence of Lyme disease.

3. Women are particularly vulnerable to complications associated with tick bites. This is related to their special role which is motherhood and raising children. Women also mostly care for the youngest children, which is why it is necessary to take educational measures to promote proper behavior and education so that women can teach and instill proper behavior of children from an early age.

4. The increase in tick bites is a threat to public health, which is why immediate preventive measures are needed. Particularly important role should be played by appropriate education in schools at all levels (also in kindergartens) as well as in public and commercial media.

5. At present, the problem of Lyma borreliosis infection is equally serious in rural and urban environments. There are no significant differences in both the occurrence of the tick and the level of knowledge of residents about this problem.

6. The overrecognition of Lyma borreliosis infection results from the imperfections in the process of reporting and registering infections and requires further actions that go beyond the scope of this work.

\section{REFERENCES}

1. Bleyenheuft C, Lernout T, Berger N, Rebolledo J, Leroy M, Robert A, et al. Epidemiological situation of Lyme borreliosis in Belgium, 2003 to 2012. Archives of Public Health 2015; 73: 33-41.

2. Pancewicz SA, Garlicki AM, Moniuszko-Malinowska A, Zajkowska J, Kondrusik M, Grygorczuk S, et al. Polish Society of Epidemiology and 
Infectious Diseases. Diagnosis and treatment of tick-borne diseases recommendations of the Polish Society of Epidemiology and Infectious Diseases. Przegl Epidemiol 2015; 69(2) :309-16, 421-8 [In Polish].

3. Stanek G, Fingerle V, Hunfeld KP, et al. Lyme borreliosis: clinical case definitions for diagnosis and management in Europe. Clin Microbiol. Infect. 2011; 17(1): 69-79.

4. Schwartz AM, Hinckley AF, Mead PS, et al. Surveillance for Lyme Disease - United States, 2008-2015. MMWR Surveill Summ. 2017; 66(22): 1-12.

5. https://stat.gov.pl/wyszukiwarka/?query=tag:lasy (access in Jan 2020).

6. Stricker RB, Middelveen MJ. Sexual transmission of Lyme disease: challenging the tickborne disease paradigm. Expert Rev Anti Infect Ther. 2015; 13(11): 1303-1306.

7. Van den Wijngaard CC, Hofhuis A, Simoes M, Rood E, van Peit W, Zeller $\mathrm{H}$, et al. Survaillance perspective on Lyme borreliosis across the European Union and European Economic Area. Euro Surveill 2017; 22(27).

8. Paradowska-Stankiewicz I, Chrześcijańska I. Lyme disease in Poland in 2012. Przegl Epidemiol. 2014; 68(2): 275-7, 375-7 [In Polish].

9. Czupryna P, Moniuszko-Malinowska A, Pancewicz S, Garkowski A, Gościk J, Siemieniako A, et al. Lyme disease in Poland - A serious problem? Adv Med Sci. 2016; 61(1): 96-100.

10. Dessau RB, van Dam AP, Fingerle V, et al. To test or not to test? Laboratory support for the diagnosis of Lyme borreliosis: a position paper of ESGBOR, the ESCMID study group for Lyme borreliosis. Clinical Microbiology and Infection: The Official Publication of the European Society of Clinical Microbiology and Infectious Diseases. https://doi.org/10.1016/j.cmi....

11. Hofhuis A, Harms M, van den Wijngaard C, Sprong H, van Pelt W, et al. Continuing increase of tick bites and Lyme disease between 1994 and 2009. Ticks Tick Borne Dis. 2015; 6(1): 69-74.

12. Zeman P, Benes C. Spatial distribution of a population at risk: an important factor for understanding the recent rise in tick-borne diseases
(Lyme borreliosis and tick-borne encephalitis in the Czech Republic). Ticks Tick Borne Dis. 2013; 4(6): 522-30.

13. Kmieciak W, Ciszewski M, Szewczyk EM. Tick-borne diseases in Poland: Prevalence and difficulties in diagnostics. Med Pr. 2016; 67(1): 73-87 [In Polish].

14. Kiewra D, Zalesny G. Relationship between temporal abundance of ticks and incidence of Lyme borreliosis in Lower Silesia regions of Poland. J Vector Ecol. 2013; 38(2): 345-52.

15. Strzelczyk JK, Gazdzicka J, Cuber P, Asman M, Trapp G, Gołabek K, et al. Prevalence of Borrelia burgdorferi sensu lato in Ixodes ricinus ticks collected from southern Poland. Acta Parasitol. 2015; 60(4): 666-74.

16. Buczek A, Ciura D, Bartosik K, Zajac Z, Kulisz J, et al. Threat of attacks of Ixodes ricinus ticks (Ixodida: Ixodidae) and Lyme borreliosis within urban heat islands in south-western Poland. Parasites \& Vectors 2014; 7: $562-71$.

17. Wojcik-Fatla A, Zając V, Sawczyn A, Sroka J, Cisak E, Dutkiewicz $\mathrm{J}$, et al. Infections and mixed infections with the selected species of Borrelia burgdorferi sensu lato complex in Ixodes ricinus ticks collected in eastern Poland: a significant increase in the course of 5 years. Exp Appl Acarol. 2016; 68(2): 197-212.

18. Berger S. Lyme disease: global status. Gideon e-book series. Gideon Informatics, Inc. Los Angeles, California, USA, 2017.18.

19. Asman M, Nowak-Chmura M, Solarz K, et al. Anaplasma phagocytophilum, Babesia microti, Borrelia burgdorferi sensu lato, and Toxoplasma gondii in Ixodes ricinus (Acari, Ixodida) ticks collected from Slowinski National Park (Northern Poland). J Vector Ecol. 2017; 42(1): 200-202.

20. Dunaj J, Moniuszko-Malinowska A, Swiecicka I, et al. Tick-borne infections and co-infections in patients with non-specific symptoms in Poland: Adv Med Sci. 2017; 63(1): 167-172.

21. Berglund J, Eitrem R, Ornstein K, et al. An epidemiologic study of Lyme disease in southern Sweden. New Engl J Med. 1995; 333(20): 1319-1327.

22. Sykes RA, Makiello P. An estimate of Lyme borreliosis incidence in Western Europe. J Public Health (Oxf) 2016; 39(1): 74-81. 